\title{
Simultaneous transapical transcatheter aortic and mitral valve replacement in a high-risk patient with a previous mitral bioprosthesis
}

\author{
Adil H. Al Kindi, MD, ${ }^{a}$ Khaled F. Salhab, MD, ${ }^{a}$ Samir Kapadia, MD, ${ }^{\mathrm{b}}$ Eric E. Roselli, MD, ${ }^{\mathrm{a}}$ \\ Amar Krishnaswamy, MD, ${ }^{\mathrm{b}}$ Andrew Grant, MD, ${ }^{\mathrm{b}}$ Emin Murat Tuzcu, MD, ${ }^{\mathrm{b}}$ and Lars G. Svensson, MD, \\ $\mathrm{PhD},{ }^{\mathrm{a}}$ Cleveland, Ohio
}

Double aortic and mitral valve replacement can now be performed with acceptable perioperative morbidity and mortality in experienced hands. However, some patients are denied conventional surgery because of increased perioperative risk. We present a patient with aortic and prosthetic mitral stenosis who was at high risk for conventional surgery that was managed with transcatheter aortic and mitral valve replacement.

\section{CLINICAL SUMMARY}

A 76-year-old woman was transferred from an outside institution with a 2-week history of weakness, nausea, and shortness of breath (New York Heart Association class III). She had hypertension, chronic obstructive pulmonary disease (forced expiratory volume in 1 second $60 \%$ of predicted), severe pulmonary hypertension (pulmonary artery systolic pressure $80 \mathrm{~mm} \mathrm{Hg}$ ), paroxysmal atrial fibrillation

From the Department of Thoracic and Cardiovascular Surgery, ${ }^{\mathrm{a}}$ and Department of Cardiovascular Medicine, ${ }^{\mathrm{b}}$ Cleveland Clinic, Cleveland, Ohio.

Disclosures: Authors have nothing to disclose with regard to commercial support.

Received for publication May 7, 2012; revisions received May 7, 2012; accepted for publication May 16, 2012; available ahead of print July 16, 2012.

Address for reprints: Lars G. Svensson, MD, PhD, Department of Thoracic and Cardiovascular Surgery, Cleveland Clinic, 9500 Euclid Avenue/Desk J4-1, Cleveland, OH 44195 (E-mail: svenssl@ccf.org).

J Thorac Cardiovasc Surg 2012;144:e90-1 $0022-5223 / \$ 36.00$

Copyright $\subset 2012$ by The American Association for Thoracic Surgery http://dx.doi.org/10.1016/j.jtcvs.2012.05.041 on warfarin, and a creatinine clearance of $36 \mathrm{~mL} / \mathrm{min}$. Her surgical history included an aorta to innominate artery bypass, mitral valve replacement for mitral stenosis with a Carpentier-Edwards pericardial valve (size 25) (Edwards Lifesciences Corp, Irvine, Calif) in 2003, and bilateral carotid endarterectomy.

Echocardiography demonstrated normal left ventricular function with a severely dilated left atrium, severe native aortic valve stenosis with gradients of (peak/mean) 57/34 $\mathrm{mm} \mathrm{Hg}$, and a valve area of $0.44 \mathrm{~cm}^{2}$. The prosthetic mitral valve showed severe stenosis due to prosthetic leaflet thickening and calcification with gradients of $32 / 17 \mathrm{~mm}$ $\mathrm{Hg}$ and trivial $1+$ regurgitation (Figure $1, A$ ). There was also moderate to severe $(3+)$ tricuspid valve regurgitation. Coronary angiography showed no significant disease. Computed tomographic angiography showed severe diffuse atherosclerotic disease of the thoracic and abdominal aorta with calcification of the iliac and common femoral arteries.

The calculated logistic European System for Cardiac Operative Risk Evaluation was 45.9\%. She was symptomatic despite maximal medical management. Her surgical risk for a conventional redo double-valve replacement was extremely high. Therefore, the decision was made to perform a transcatheter double-valve replacement via a transapical approach.

The procedure was performed in a hybrid operating room by a team consisting of cardiac surgeons, cardiologists, and
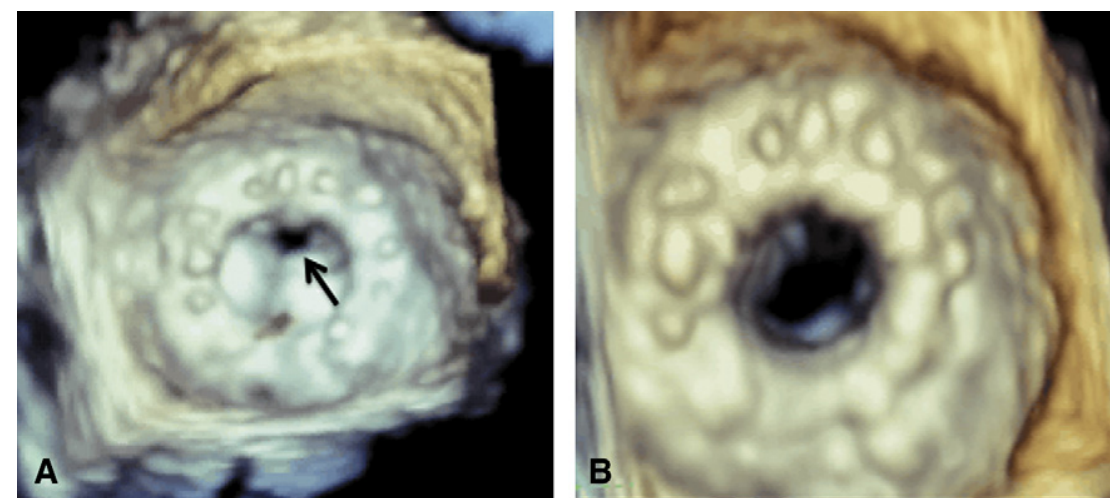

FIGURE 1. Simultaneous transapical TAVR and valve-in-valve replacement of a failing bioprosthetic mitral valve. A, Intraoperative echocardiography showing severe bioprosthetic mitral stenosis (arrow, left atrial view). B, Mitral valve after Sapien (Edwards Lifesciences Corp, Irvine, Calif) valve-invalve implantation. 

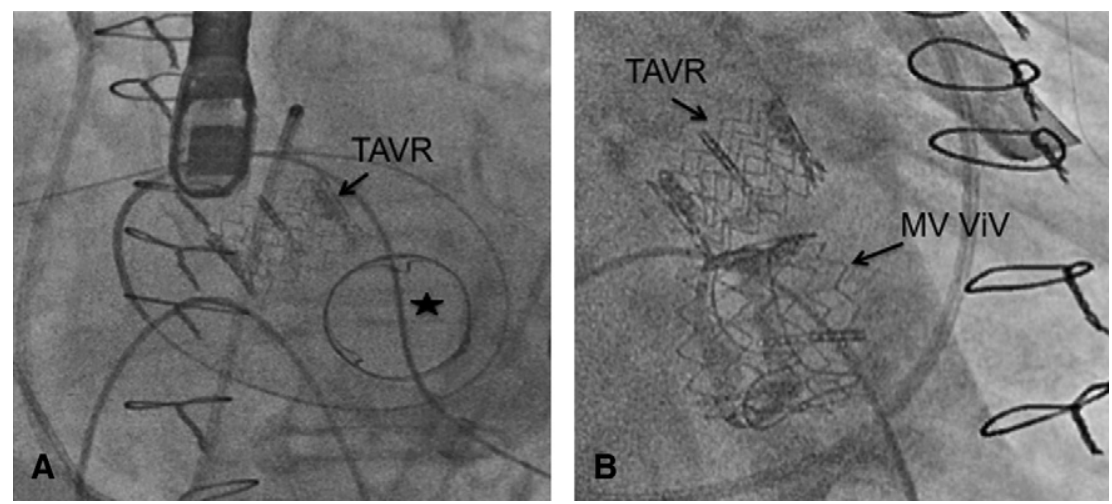

FIGURE 2. A, Fluoroscopic view after deploying the aortic valve with the wire through the prosthetic mitral valve (inducated by asterisk) (left anterior oblique projection). B, Both valves in place (right anterior oblique projection). TAVR, Transcatheter aortic valve replacement; $M V$, mitral valve; ViV, valve-in-valve.

a cardiac anesthesiologist. Access to the left ventricular apex was gained via a mini anterolateral thoracotomy through the fifth intercostal space as determined by computed tomography of the chest. Pledgeted purse-string sutures were placed on the left ventricular apex. Preoperative and intraoperative echocardiography confirmed that the aortic annulus was $21 \mathrm{~mm}$. After performing balloon valvuloplasty of the aortic valve, a 23-mm Edwards Sapien transcatheter heart valve (Edwards Lifesciences Corp) was deployed in an antegrade fashion (Figure 2, A). Attention was then turned to the mitral prosthesis. A wire was passed through the prosthetic mitral valve, but no balloon valvuloplasty was performed. The inner internal diameter of the mitral prosthesis on echocardiography was $23 \mathrm{~mm}$. A 26-mm Edwards Sapien transcatheter heart valve was deployed in a retrograde fashion as in the transfemoral approach for the aortic valve (Figure 1, B). Both valves were deployed under fluoroscopy and echocardiography guidance confirming correct position (Figure 2, B). Postoperative echocardiography demonstrated trace paravalvular leak and minimal valve gradients. After an initial prolonged intubation, the patient continues to do well.

\section{DISCUSSION}

In recent years, transcatheter aortic valve replacement (TAVR) has emerged as a feasible and reproducible procedure in high-risk patients. Small and large series demonstrated that TAVR via the transapical approach has good results with acceptable morbidity and mortality. ${ }^{1}$ The outcomes are comparable to the retrograde approach via the transfemoral artery.

With these successes, the use of TAVR has been expanded to include patients who require redo valve replacement. Case reports and small series have shown the feasibility of valve-in-valve replacement in both the aortic ${ }^{2}$ and mitral positions using a transcatheter valve that was designed for the native aortic position. ${ }^{3}$ In the mitral position, the presence of the prosthetic valve-sewing ring allows anchoring of the percutaneous aortic valve.
In this report, we demonstrate the successful simultaneous deployment of the Edwards Sapien transcatheter heart valve in both the aortic and mitral positions. The aortic valve was deployed successfully in the native aortic annulus, and the mitral valve was a valve-in-valve deployment. Both deployed valves demonstrated excellent post-deployment hemodynamics. Despite the patient's high-risk profile, she did well in the postoperative period.

\section{CONCLUSIONS}

The gold standard for the management of valve stenosis is valve replacement, including those who require reoperations. ${ }^{4,5}$ However, high perioperative risk with major morbidity and potential mortality outweighs the symptomatic and survival benefit of a conventional valve replacement in some patients. We show that double-valve transcatheter replacement via the transapical approach is technically feasible with the current available technology. However, the results of this procedure must be analyzed with caution because we do not yet have mid- and long-term results of the durability and performance of these valves when deployed simultaneously.

\section{ADDENDUM}

Six weeks after surgery, the patient developed gut gangrene, which she did not survive.

\section{References}

1. Kempfert J, Rastan A, Holzhey D, Linke A, Schuler G, van Linden A, et al. Transapical aortic valve implantation: analysis of risk factors and learning experience in 299 patients. Circulation. 2011;124(11 Suppl):S124-9.

2. Cockburn J, Trivedi U, Hildick-Smith D. Transaortic transcatheter aortic valve implantation within a previous bioprosthetic aortic valve replacement. Catheter Cardiovasc Interv. 2011;78:479-84.

3. Cerillo AG, Chiaramonti F, Murzi M, Bevilacqua S, Cerone E, Palmieri C, et al. Transcatheter valve in valve implantation for failed mitral and tricuspid bioprosthesis. Catheter Cardiovasc Interv. 2011;78:987-95.

4. Svensson LG, Gillinov AM, Blackstone EH, Houghtaling PL, Kim KH, Pettersson GB, et al. Does right thoracotomy increase the risk of mitral valve reoperation? J Thorac Cardiovasc Surg. 2007;134:677-82.

5. Svensson LG, Blackstone EH, Cosgrove DM III. Surgical options in young adults with aortic valve disease. Curr Probl Cardiol. 2003;28:417-80. 